\title{
Bioactivity of Thyroid Hormone Analogs at Cancer Cells
}

\author{
Paul J. Davis ${ }^{1,2 *}$, Heng-Yuan Tang ${ }^{2}$, Aleck Hercbergs ${ }^{3}$, Hung-Yun Lin ${ }^{4,5,6,7}$, \\ Kelly A. Keating ${ }^{2}$ and Shaker A. Mousa ${ }^{2}$
}

${ }^{1}$ Department of Medicine, Albany Medical College, Albany, NY, United States, ${ }^{2}$ Pharmaceutical Research Institute, Albany College of Pharmacy and Health Sciences, Rensselaer, NY, United States, ${ }^{3}$ Department of Radiation Oncology, The Cleveland Clinic, Cleveland, $\mathrm{OH}$, United States, ${ }^{4} \mathrm{PhD}$ Program for Cancer Molecular Biology and Drug Discovery, College of Medical Science and Technology, Taipei Medical University, Taipei, Taiwan, ${ }^{5}$ Taipei Cancer Center, Taipei Medical University, Taipei, Taiwan, ${ }^{6}$ Traditional Herbal Medicine Research Center of Taipei Medical University Hospital, Taipei Medical University, Taipei, Taiwan, ${ }^{7}$ TMU Research Center of Cancer Translational Medicine, Taipei Medical University, Taipei, Taiwan

OPEN ACCESS

Edited by:

Roberta Malaguarnera, Università degli studi Magna Græcia di

Catanzaro, Italy

Reviewed by:

Rosario Le Moli,

Università degli Studi di Catania, Italy Paolo Ciana,

University of Milan, Italy

*Correspondence: Paul J. Davis

pdavis.ordwayst@gmail.com

Specialty section:

This article was submitted to

Cancer Endocrinology,

a section of the journal

Frontiers in Endocrinology

Received: 24 September 2018 Accepted: 21 November 2018 Published: 04 December 2018

Citation:

Davis PJ, Tang $H-Y$, Hercbergs $A$, Lin $H-Y$, Keating $K A$ and Mousa SA (2018) Bioactivity of Thyroid Hormone Analogs at Cancer Cells. Front. Endocrinol. 9:739. doi: 10.3389/fendo.2018.00739
In the context of genomic thyroid hormone actions in normal (noncancer) cells that involve primary interactions with nuclear thyroid hormone receptors (TRs), L-thyroxine (T4), and 3,3', $5^{\prime}$-triiodo-L-thyronine (reverse T3, rT3) have little bioactivity. In terms of TRs, T4 is a prohormone from which the active nuclear ligand, 3,5,3'-triido-L-thyronine (T3), is generated by deiodination. Deaminated T4 and T3 metabolites have different genomic effects: tetraiodothyroacetic acid (tetrac) is a low grade thyromimetic derivative of T4, whereas triiodothyroacetic acid (triac), the acetic acid metabolite of T3, has substantial thyromimetic activity. In cancer cells, the cell surface receptor for thyroid hormone on integrin $\alpha \vee \beta 3$ mediates non-genomic actions of thyroid hormone analogs. The integrin is expressed in large measure by cancer cells and dividing endothelial cells and has a substantially different panel of responses to thyroid hormone analogs. At $\alpha \vee \beta 3$, T4 is a potent proliferative, anti-apoptotic and pro-angiogenic hormone and is the primary ligand. rT3 may also be proliferative at this site. In contrast, tetrac and triac are antagonists of $\mathrm{T} 4$ at $\alpha \vee \beta 3$, but also have anticancer properties at this site that are independent of their effects on the binding of T4.

Keywords: L-thyroxine, tetrac, triac, reverse T3, non-genomic actions

\section{INTRODUCTION}

The concept that the bioactivity of thyroid hormone is expressed by 3,5,3'-triiodo-L-thyronine (T3) has served to identify the critical metabolic and protein synthetic functions of the hormone that are dependent upon interactions of T3 with nuclear thyroid hormone receptors (TRs) in normal cells $(1,2)$. The T3-TR mechanism of action of thyroid hormone is designated genomic. T3 also has a limited number of effects initiated in cytoplasm or at the plasma membrane that are independent of TRs and thus are non-genomic in mechanism (1). T3 has also been recognized to have specific functions in cancer cells that may depend upon TR mutation $(3,4)$. The primary thyroid hormone product of the thyroid gland is L-thyroxine (T4), whose status as a prohormone for T3 has been fully appreciated to be defined by deiodinases in a variety of non-thyroid tissues that generate T3 by outer thyroid hormone ring deiodination at the 5' position of the diphenyl ether structure of iodothyronines (5). Inner ring deiodination at the 5 position produces reverse T3 (rT3), which is generally regarded as inactive. Modifications of the alanine side chain of iodothyronines occur naturally at the cellular level, but only to a limited degree, and yields tetraiodothyroacetic acid 
(tetrac) and triiodothyroacetic acid (triac), which have some metabolic activities (6).

The appreciation of the existence of a receptor for thyroid hormone analogs on the plasma membrane of cancer and rapidly dividing endothelial cells $(1,7,8)$ has enabled the recognition of functions of thyroid hormone analogs that were previously thought to be inactive. The cell surface receptor is on the extracellular domain of integrin $\alpha \mathrm{v} \beta 3$. The plasma membrane receptor for thyroid hormone has no structural homologies with TRs. At this receptor, T4 promotes cancer cell proliferation, supports anti-apoptosis and enhances angiogenesis because of its presence on endothelial cells (9-11). Tetrac inhibits the actions of $\mathrm{T} 4$ at the integrin and in the absence of T4 has a variety of actions on expression of specific genes. That is, T4 and tetrac affect the activities of a number of signal transduction pathways that downstream modulate differentially the transcription of a number of genes $(8,12$, 13). The actions of $\mathrm{T} 4$ and tetrac at $\alpha \mathrm{v} \beta 3$ are non-genomic in that they do not directly involve TRs or require hormonal presence in the nucleus. Operationally, however, both genomic and non-genomic actions of thyroid hormones may culminate in specific gene transcription. The receptor on $\alpha v \beta 3$ can also control the trafficking of intracellular proteins-including the transfer of cytoplasmic TRs and estrogen receptor- $\alpha$ into the nuclear compartment of cancer cells-and regulate the phosphorylation/activation of TRs $(1,14)$.

Integrins are a family of two dozen heterodimeric structural proteins of the plasma membrane and are critical to tissue structure and to cell migration. They interact importantly with extracellular matrix proteins and with other cells (15). The receptor for thyroid hormone on $\alpha \mathrm{v} \beta 3$ is the first small molecule binding site recognized on integrins, but subsequently discrete receptors on $\alpha \mathrm{v} \beta 3$ have been reported for other small molecules, including dihydrotestosterone (DHT) (16) and the stilbene, resveratrol (17). Integrin $\alpha \mathrm{v} \beta 3$ is expressed to a limited degree by non-dividing normal, i.e., non-cancer, cells, but the function of such cells does not appear to be affected by any interactions of T4 and the integrin that may occur. This may reflect the ("non-activated") physical state of $\alpha v \beta 3$ in non-cancer cells (18). The integrin is functional, however, on the surface of platelets, reflecting the presence of fractions of the plasma membrane of megakaryocytes. T4 has been shown to induce platelet aggregation via $\alpha v \beta 3$ (19).

In the succeeding sections, we briefly review the bioactivities of thyroid hormone analogs at the iodothyronine receptor on integrin $\alpha \mathrm{v} \beta 3$.

\section{BIOACTIVITY OF T4 AT $\alpha$ V $\beta 3$}

An early demonstration of the non-genomic activity of T4 was its conversion of soluble actin to fibrous actin F-actin $(8,20)$. This was initially demonstrated in astrocytes and glial cells. The molecular basis of this action of the hormone is incompletely understood, but appears to involve a truncated $\operatorname{TR} \alpha(\mathrm{TR} \Delta \alpha 1)$ isoform in cytoplasm (8). This isoform does not contain a nuclear localization signal. T3 does not affect the state of actin in cells.
Regulation of the state of actin is of obvious importance to both normal and malignant cells.

In 2004, T4 was shown to be pro-angiogenic in the chick choriollantoic membrane (CAM) model. The CAM model has important dependency on $\alpha \mathrm{v} \beta 3$, and antibody to this integrin blocked the action of $\mathrm{T} 4$ on new blood vessel formation. Physiological concentrations of free $\mathrm{T} 4$ were shown to be active in this system (21). In this model system, the inhibition of conversion of $\mathrm{T} 4$ to $\mathrm{T} 3 \mathrm{did}$ not affect the action of $\mathrm{T} 4$ on the state of actin. This action of T4 was shown to be initiated at integrin $\alpha v \beta 3$, leading to a series of studies characterizing the receptor on the head of the extracellular domain of the integrin. While integrins are found on both normal cells and malignant cells, $\alpha v \beta 3$ is particularly generously expressed by cancer cells and rapidly dividing endothelial cells $(8,15)$. It and other integrins are very important to cell-cell interactions and cell-extracellular matrix (ECM) proteins that underlie tissue integrity and the orientation of motile cells. As noted above, thyroxine was the first small molecule to be found to bind specifically to $\alpha v \beta 3$.

At the integrin, T4 was found to have a number of cancerrelevant functions mediated by $\alpha v \beta 3(1,8,9,12)$. These included stimulation of cell proliferation and anti-apoptosis (10). Such properties relied upon activation of signaling pathways [mitogen activated protein kinase [MAPK]/ERK1/2; phosphatidylinositol 3-kinase (PI3K)] that culminated downstream in specific gene transcription $(1,7,8,12)$. In contrast to the genomic actions of T3 that depend on primary intranuclear interactions of T3 with activated TRs, the actions of T4 on cancer cell proliferation, angiogenesis and apoptosis depended on the location of the hormone on the cell surface $(1,8)$.

Among the genes whose expression is differentially regulated from the plasma membrane and $\alpha v \beta 3$ are genes for matrix metalloproteinases, basic fibroblast growth factor (FGF2), hypoxia-inducible factor- $1 \alpha$ (HIF-1 $\alpha$ ), cyclooxygenase-2 (COX2) and, interestingly, $\operatorname{TR} \alpha$ and $\operatorname{TR} \beta$; transcription of all of the preceding genes is upregulated by T4 (8). The control of TR gene expression from the cell surface is an example of overlapping non-genomic and genomic effects of thyroid hormone (14). Downregulated is expression of the genes for pro-apoptotic APAF1, CASP3, PMAIP1, and BBC3 (8). The relevance of these genes to cancer cell survival is clear. Tetrac is a naturally occurring derivative of $\mathrm{T} 4$ that blocks the binding of T4 (and T3) to the receptor on $\alpha v \beta 3$. In the absence of T4, however, tetrac and tetrac that is modified by covalent binding to a nanoparticle or polymer have effects on expression of several hundred genes (12), e.g., angiogenesis-linked vascular endothelial growth factor A (VEGFA), epidermal growth factor receptor (EGFR), cell survival pathway genes XIAP and MCL1 and cell cycle-regulating genes. The latter include genes for multiple cyclins and a cyclin-dependent kinase. Genes relevant to radioresistance and chemoresistance, e.g., p-glycoprotein $(P-g p)$ are also affected by tetrac. The expression of all of these genes is decreased by unmodified or modified tetrac, indicating that the modified tetrac compounds have applications as experimental chemotherapeutic agents. Because tetrac is an antagonist of T4, a possible implication of these studies of tetrac is that T4 may be a stimulator of the transcription of this 
panel of genes. This possibility has not yet been systematically examined.

\section{BIOACTIVITY OF rT3}

The conversion of T4 to rT3, rather than to T3, generates a thyroid hormone analog with no genomic actions. This 5deiodination process is a function of the action of deiodinase 3 (DIO3, D3) or deiodinase 1 (DIO1, D1) (6). rT3, however, was found a number of years ago to be capable of converting soluble actin to F-actin (20), just as T4 does. In developing mouse cerebellum, astrocytes lacking TRs recover normal actin function with transfection of TR $\Delta \alpha 1$ (22).

rT3 may also modulate avian lipid metabolism response to epinephrine and steroids (23). The activity of DIO2 (D2) in murine neuroblastoma cells may also be reduced by rT3 (24). Thus, a set of observations in disparate model systems indicates that rT3 has bioactivity. Against this background, we have recently tested rT3 for proliferative activity in glioblastoma cells. We had previously shown that T4 enhances proliferation of several glioma cell lines (25) and that chemically modified tetrac, a T4 antagonist, inhibited the growth of glioblastoma xenografts (26). In the recent studies, the glioblastoma cell line U87MG and two primary cultures of human GBM cells significantly increased their rates of proliferation in vitro when exposed to T4, as expected, but also to rT3 (27). These studies must be extended and expanded to include other types of cancer. Confirmation would indicate that conversion of T4 to rT3, rather than to T3, offers cancer cells another thyroid hormone analog support mechanism. Indeed, T3 at physiological concentrations may provide no stimulus to tumor cell proliferation, as a recent clinical study in endstage cancer patients of euthyroid hypothyroxinemia suggests (28). In that study, stabilization or regression of advanced disease was achieved with inhibition of endogenous thyroid hormone production by methimazole and maintenance of the euthyroid state with exogenous T3. Elimination of host $\mathrm{T} 4$ production in such patients also minimizes production of rT3.

We can conclude that rT3 has bioactivity and that, possibly, this thyroid hormone analog has proliferative activity on certain cancer cells.

\section{TETRAC AND TRIIODOTHYROACETIC ACID (TRIAC)}

In the nucleus, tetrac and triac are thyromimetic (6). Triac has some TR $\beta$-selectivity that has favored its use over tetrac in thyroid hormone-resistant patients to suppress host thyrotropin (TSH) (6), but each agent has been used in this setting. Advantages of the genomic effects of these deaminated derivates of T4 and T3 have also been sought in management of obesity and hyperlipidemia. All such applications involve hormone effects on non-cancer cells.

Because of the heightened expression of $\alpha \mathrm{v} \beta 3$ in cancer cells, non-genomic actions of tetrac and triac are seen in such cells. Both are anti-proliferative in cancer cells (8).
Tetrac has been chemically modified to a nanoparticulate drug (Nanotetrac, NDAT) by covalent coupling to large molecules such as poly-lactic-co-glycolic acid (PLGA) to minimize its access to the intranuclear compartment when the agent is internalized by cells. Tetrac is thyromimetic in the intranuclear compartment (29). Chemically modified tetrac blocks binding of T4 (and T3) to the thyroid hormone receptor on $\alpha \mathrm{v} \beta 3$, thus eliminating some of the cancer support properties of T4 that were described above. In addition, in the absence of T4, NDAT or tetrac in another formulation in our laboratory in which it is covalently bound to polyethylene glycol (PEG) has actions downstream of the integrin on expression of a large number of cancer-relevant genes $(8,12,13)$. The actions are anti-proliferative, pro-apoptotic and anti-angiogenic by multiple mechanisms. Modified tetrac may also impair DNA repair that is important to cancer cell resistance to radiation (30). Finally, by suppressing expression of the $P$ - $g p$ gene, modified tetrac may reduce chemoresistance (31), since the plasma membrane Pgp pump exports certain cancer chemotherapeutic drugs (31, 32).

$X$-irradiation has been shown to activate integrin $\alpha v \beta 3$ (18), an effect that is primarily on the $\beta 3$ monomer and that is thought to contribute to radioresistance (33). This effect is blocked by tetrac (as NDAT).

The actions of triac on cancer cells have been incompletely characterized. It is clear, however, that triac can act at integrin $\alpha v \beta 3$ to non-genomically initiate apoptosis in human ovarian cancer cells (34). Triac does not appear to have effects on mitochondria in tumor cells (35). How important genomic effects of triac may be in cancers cells is not known. Triac not surprisingly binds to a genetically modified TR $\beta$ that trafficks between cytoplasm and the nucleus in a cancer cell model generated to detect endocrine disrupting chemicals (36), and triac binds to TR in noncancer cells (37) and has been used clinically to treat certain forms of thyroid hormone resistance because of its facilitated transport across the plasma membrane of normal cells.

It should also be noted that thyroid hormone analogs affect abundance of certain microRNAs (mRNAs) in cancer cells. We have pointed out that Nanotetrac differentially regulates transcription of miR-21 and miR-15A in tumor cells $(12,38)$ and in so doing is anti-angiogenic and decreases metastatic potential of cancer cells. The effects of T4 on expression of these miRNAs has not yet been examined.

What is apparent is that the thyromimetic properties of deaminated thyroid hormone, particularly tetrac, are importantly overshadowed in cancer cells by its anticancer actions that are expressed via integrin $\alpha \mathrm{v} \beta 3$. Triac also has anticancer activity at the integrin.

\section{CONCLUSIONS}

The existence of integrin $\alpha v \beta 3$ on the surface of cancer cells and rapidly dividing endothelial cells provides new insights into the bioactivities of a number of iodothyronines. T4 is a potent 
pro-angiogenic hormone with proliferative-enhancing activity in cancer cells, whereas in the context of nuclear TRs, T4 is simply a prohormone for T3. At the thyroid hormone receptor on $\alpha v \beta 3$, rT3 may also be biologically active. Finally, deaminated thyroid hormone analogs are weak thyromimetic agents at TRs, but are potent anti-T4 agents in cancer cells and also have a number of anticancer effects that are independent of their activity as blockers of T4 binding to the cell surface receptor.

What about $\mathrm{T} 3$ at $\alpha \mathrm{v} \beta 3$ ? In higher than physiologic concentrations, T3 can stimulate cancer cell proliferation at the receptor on the integrin $(8,39)$, but as the induced clinical state of euthyroid hypothyroxinemia in cancer patients suggests, maintenance of euthyroidism exclusively with T3 does not appear to promote tumor growth (28).

The scope of this review is limited by the relatively small number of types of solid tumors that have been studied for possible effects of thyroid hormone analogs. Leukemic cells have not been examined for trophic or antagonistic effects of thyroid hormones. Additional clinical studies are needed of the effects of induction of euthyroid hypothyroxinemia on tumor behavior.

\section{REFERENCES}

1. Cheng SY, Leonard JL, Davis PJ. Molecular aspects of thyroid hormone actions. Endocr Rev. (2010) 31:139-70. doi: 10.1210/er.2009-0007

2. Vella KR, Hollenberg AN. The actions of thyroid hormone signaling in the nucleus. Mol Cell Endocrinol. (2017) 458:127-35. doi: 10.1016/j.mce.2017.03.001

3. Lu C, Cheng SY. Extranuclear signaling of mutated thyroid hormone receptors in promoting metastatic spread in thyroid carcinogenesis. Steroids (2011) 76:885-91. doi: 10.1016/j.steroids.2011.03.016

4. Guigon CJ, Cheng SY. Novel non-genomic signaling of thyroid hormone receptors in thyroid carcinogenesis. Mol Cell Endocrinol. (2009) 308:63-9. doi: 10.1016/j.mce.2009.01.007

5. Peeters RP, Visser TJ. Metabolism of Thyroid Hormone. In: De Groot LJ, Chrousos G, Dungan K, Feingold KR, Grossman A, Hershman JM, et al., editors. Endotext. South Dartmouth, MA: MDText.com, Inc. (2000)

6. Senese R, Cioffi F, de Lange P, Goglia F, Lanni A. Thyroid: biological actions of "nonclassical" thyroid hormones. J Endocrinol. (2014) 221:R1-12. doi: 10.1530/JOE-13-0573

7. Bergh JJ, Lin HY, Lansing L, Mohamed SN, Davis FB, Mousa S, et al. Integrin $\alpha \mathrm{V} \beta 3$ contains a cell surface receptor site for thyroid hormone that is linked to activation of mitogen-activated protein kinase and induction of angiogenesis. Endocrinology (2005) 146:2864-71. doi: 10.1210/en.2005-0102

8. Davis PJ, Goglia F, Leonard JL. Nongenomic actions of thyroid hormone. Nat Rev Endocrinol. (2016) 12:111-21. doi: 10.1038/nrendo.2015.205

9. Mousa SA, Lin HY, Tang HY, Hercbergs A, Luidens MK, Davis PJ. Modulation of angiogenesis by thyroid hormone and hormone analogues: implications for cancer management. Angiogenesis (2014) 17:463-9. doi: 10.1007/s10456-014-9418-5

10. Lin HY, Chin YT, Yang YC, Lai HY, Wang-Peng J, Liu LF, et al. Thyroid hormone, cancer, and apoptosis. Compr Physiol. (2016) 6:1221-37. doi: 10.1002/cphy.c150035

11. Davis PJ, Sudha T, Lin HY, Mousa SA. Thyroid hormone, hormone analogs, and angiogenesis. Compr Physiol. (2015) 6:353-62. doi: 10.1002/cphy.c150011

12. Davis PJ, Glinsky GV, Lin H-Y, Leith JT, Hercbergs A, Tang H-Y, et al. Cancer cell gene expression modulated from plasma membrane integrin $\alpha \mathrm{v} \beta 3$ by thyroid hormone and nanoparticulate tetrac. Front Endocrinol. (2014) 5:240. doi: 10.3389/fendo.2014.00240

13. Glinskii AB, Glinsky GV, Lin HY, Tang HY, Sun M, Davis FB, et al. Modification of survival pathway gene expression in human breast cancer
An inference of the discussion of tetrac is the need to test clinically the anticancer efficacy of chemically modified tetrac that has been demonstrated experimentally in cells and in xenografts.

\section{AUTHOR CONTRIBUTIONS}

All authors listed have made a substantial, direct and intellectual contribution to the work, and approved it for publication.

\section{FUNDING}

The work described here was supported in part by the TMU Research Center of Cancer Translational Medicine from The Featured Area Research Center Program within the framework of the Higher Education Sprout project by the Ministry of Education (MOE) in Taiwan. A grant from NanoPharmaceuticals LLC (Rensselaer, NY, USA) also provided support.

cells by tetraiodothyroacetic acid (tetrac). Cell Cycle (2009) 8:3562-70. doi: $10.4161 /$ cc.8.21.9963

14. Hammes SR, Davis PJ. Overlapping nongenomic and genomic actions of thyroid hormone and steroids. Best Pract Res Clin Endocrinol Metab. (2015) 29:581-93. doi: 10.1016/j.beem.2015.04.001

15. Desgrosellier JS, Cheresh DA. Integrins in cancer: biological implications and therapeutic opportunities. Nat Rev Cancer (2010) 10:9-22. doi: $10.1038 / \mathrm{nrc} 2748$

16. Lin HY, Sun M, Lin C, Tang HY, London D, Shih A, et al. Androgen-induced human breast cancer cell proliferation is mediated by discrete mechanisms in estrogen receptor- $\alpha$-positive and -negative breast cancer cells. J Steroid Biochem Mol Biol. (2009) 113:182-8. doi: 10.1016/j.jsbmb.2008.12.010

17. Lin HY, Lansing L, Merillon JM, Davis FB, Tang HY, Shih A, et al. Integrin $\alpha \mathrm{V} \beta 3$ contains a receptor site for resveratrol. FASEB J. (2006) 20:1742-4. doi: 10.1096/fj.06-5743fje

18. Leith JT, Hercbergs A, Kenney S, Mousa SA, Davis PJ. Activation of tumor cell integrin $\alpha \mathrm{v} \beta 3$ by radiation and reversal of activation by chemically modified tetraiodothyroacetic acid (tetrac). Endocr Res. (2018) 43:215-9. doi: 10.1080/07435800.2018.1456550

19. Mousa SS, Davis FB, Davis PJ, Mousa SA. Human platelet aggregation and degranulation is induced in vitro by L-thyroxine, but not by 3,5,3'-triiodo-L-thyronine or diiodothyropropionic acid (DITPA). Clin Appl Thromb Hemost. (2010) 16:288-93. doi: 10.1177/10760296093 48315

20. Leonard JL, Farwell AP. Thyroid hormone-regulated actin polymerization in brain. Thyroid (1997) 7:147-51. doi: 10.1089/thy.1997.7.147

21. Davis FB, Mousa SA, O'Connor L, Mohamed S, Lin HY, Cao HJ, et al. Proangiogenic action of thyroid hormone is fibroblast growth factordependent and is initiated at the cell surface. Circ Res. (2004) 94:1500-6. doi: 10.1161/01.RES.0000130784.90237.4a

22. Flamant F, Samarut J. Thyroid hormone receptors: lessons from knockout and knock-in mutant mice. Trends Endocrinol Metab. (2003) 14:85-90. doi: 10.1016/S1043-2760(02)00043-7

23. Bobek S, Sechman A, Niezgoda J, Jacek T. Reverse 3,3'5'-triiodothyronine suppresses increase in free fatty acids in chickens elicited by dexamethasone or adrenaline. J Vet Med A Physiol Pathol Clin Med. (2002) 49:121-4. doi: 10.1046/j.1439-0442.2002.00343.x

24. Gavin LA, Moeller M, Shoback D, Cavalieri RR. Reverse T3 and modulators of the calcium messenger system rapidly decrease T4-5'-deiodinase II activity in cultured mouse neuroblastoma cells. Thyroidology (1988) 5-12. 
25. Davis FB, Tang HY, Shih A, Keating T, Lansing L, Hercbergs A, et al. Acting via a cell surface receptor, thyroid hormone is a growth factor for glioma cells. Cancer Res. (2006) 66:7270-5. doi: 10.1158/0008-5472.CAN-05-4365

26. Sudha T, Bharali DJ, Sell S, Darwish NHE, Davis PJ, Mousa SA. Nanoparticulate tetrac inhibits growth and vascularity of glioblastoma xenografts. Horm. Cancer (2017) 8:157-65. doi: 10.1007/s12672-017-0293-6

27. Hercbergs A, Mousa SA, Davis PJ. Nonthyroidal illness syndrome and thyroid hormone actions at integrin $\alpha v \beta 3$. J Clin Endocrinol Metab. (2018) 103:12915. doi: 10.1210/jc.2017-01939

28. Hercbergs A, Johnson RE, Ashur-Fabian O, Garfield DH, Davis PJ. Medically induced euthyroid hypothyroxinemia may extend survival in compassionate need cancer patients: an observational study. Oncologist (2015) 20:72-6. doi: 10.1634/theoncologist.2014-0308

29. Bharali DJ, Yalcin M, Davis PJ, Mousa SA. Tetraiodothyroacetic acid-conjugated PLGA nanoparticles: a nanomedicine approach to treat drug-resistant breast cancer. Nanomedicine (2013) 8:1943-54. doi: $10.2217 / \mathrm{nnm} .12 .200$

30. Hercbergs AH, Lin HY, Davis FB, Davis PJ, Leith JT. Radiosensitization and production of DNA double-strand breaks in U87MG brain tumor cells induced by tetraiodothyroacetic acid (tetrac). Cell Cycle (2011) 10:352-7. doi: $10.4161 /$ cc.10.2.14641

31. Davis PJ, Incerpi S, Lin HY, Tang HY, Sudha T, Mousa SA. Thyroid hormone and P-glycoprotein in tumor cells. Biomed Res Int. (2015) 2015:168427. doi: $10.1155 / 2015 / 168427$

32. Lin HY, Tang HY, Davis FB, Mousa SA, Incerpi S, Luidens MK, et al. Nongenomic regulation by thyroid hormone of plasma membrane ion and small molecule pumps. Discov Med. (2012) 14:199-206.

33. Leith JT, Mousa SA, Hercbergs A, Lin HY, Davis PJ. Radioresistance of cancer cells, integrin $\alpha v \beta 3$ and thyroid hormone Oncotarget (2018)

34. Shinderman-Maman E, Cohen K, Moskovich D, Hercbergs A, Werner H, Davis PJ, et al. Thyroid hormones derivatives reduce proliferation and induce cell death and DNA damage in ovarian cancer. Sci Rep. (2017) 7:16475. doi: $10.1038 / \mathrm{s} 41598-017-16593-\mathrm{x}$
35. Kvetny J, Bomholt T, Pedersen P, Wilms L, Anthonsen S, Larsen J. Thyroid hormone effect on human mitochondria measured by flow cytometry. Scand J Clin Lab Invest. (2009) 69:772-6. doi: 10.3109/00365510903154752

36. Stavreva DA, Varticovski L, Levkova L, George AA, Davis L, Pegoraro $\mathrm{G}$, et al. Novel cell-based assay for detection of thyroid receptor betainteracting environmental contaminants. Toxicology (2016) 368-369:69-79. doi: 10.1016/j.tox.2016.08.012

37. Groeneweg S, Peeters RP, Visser TJ, Visser WE. Triiodothyroacetic acid in health and disease. J Endocrinol. (2017) 234:R99-121. doi: 10.1530/JOE-17-0113

38. Mousa SA, Glinsky GV, Lin HY, Ashur-Fabian O, Hercbergs A, Keating KA, et al. Contributions of thyroid hormone to cancer metastasis. Biomedicines (2018) 6:E89. doi: 10.3390/biomedicines6030089

39. Lin HY, Landersdorfer CB, London D, Meng R, Lim CU, Lin C, et al. Pharmacodynamic modeling of anti-cancer activity of tetraiodothyroacetic acid in a perfused cell culture system. PLoS Comput Biol. (2011) 7:e1001073. doi: 10.1371/journal.pcbi.1001073

Conflict of Interest Statement: Coauthors PJD and SAM have stock holdings in a company that is developing modified tetrac as an anticancer agent and author KAK is a paid consultant of NanoPharmaceuticals LLC.

The remaining authors declare that the research was conducted in the absence of any commercial or financial relationships that could be construed as a potential conflict of interest.

Copyright (C) 2018 Davis, Tang, Hercbergs, Lin, Keating and Mousa. This is an openaccess article distributed under the terms of the Creative Commons Attribution License (CC BY). The use, distribution or reproduction in other forums is permitted, provided the original author(s) and the copyright owner(s) are credited and that the original publication in this journal is cited, in accordance with accepted academic practice. No use, distribution or reproduction is permitted which does not comply with these terms. 